\title{
Beta-lactam Antibiotics Residues in Milk Samples Collected in Northern Tunisia
}

\author{
Abderraouf Gritli ${ }^{1, *}$, Yahia Teber ${ }^{2}$, Rim Lahmar $^{2}$, Samir Ben Youssef ${ }^{2}$ \\ ${ }^{1}$ General Directorate of Military Health, Tunis, Tunisia. \\ ${ }^{2}$ Laboratory of Pharmacy and Toxicology, National School of Veterinary Medicine of Sidi Thabet, 2020 Sidi Thabet, Manouba \\ University, Manouba, Tunisia.
}

\begin{abstract}
How to cite this paper: Abderraouf Gritli, Yahia Teber, Rim Lahmar, Samir Ben Youssef. (2021) Beta-lactam Antibiotics Residues in Milk Samples Collected in Northern Tunisia. International Journal of Food Science and Agriculture, 5(3), 550-554.

DOI: 10.26855/ijfsa.2021.09.027
\end{abstract}

Received: July 12, 2021

Accepted: August 10, 2021

Published: September 23, 2021

*Corresponding author: Abderraouf Gritli, General Directorate of Military Health, Tunis, Tunisia.

Email: raoufgritli@yahoo.fr

\begin{abstract}
Antibiotics are one of the most important drugs in large animal veterinary practice. However, antibiotics and especially $\beta$-lactam can be found as residues in different animal products particularly in milk from treated cows. The present survey was conducted between July 2016 and June 2017 in four governorates from Northern Tunisia, namely Jendouba, Béja, Kef and Siliana. A total of 10.699 bulk cow's milk samples were collected and tested for the presence of $\beta$-lactam residues using the Penzym ${ }^{\circledR}$ test. Among them, 14 were positive. Even if the contamination rate was low $(0.13 \%)$, the quantity of refused milk due to presence of $\beta$-lactam residues was relatively high $\left(102.10^{3} \mathrm{~L}\right)$ which represents $2.6 \%$ of the total volume of refused milk $\left(3.874 .10^{3} \mathrm{~L}\right)$. Milk samples collected from the Kef governorate showed the highest proportion of antibiotic residues $(0.64 \%)$, followed by the governorate of Béja $(0.13 \%)$ and the governorate of Jendouba $(0.07 \%)$. The presence of $\beta$-lactam residues in milk represents a real threat to animal and human health, systematic monitoring could be implemented in Tunisia for all milk productions in order to reduce these risks.
\end{abstract}

\section{Keywords}

Antibiotics, Residues, $\beta$-lactams, Milk, Tunisia

\section{Introduction}

Antibiotics are important therapeutic tools to treat both animal and human diseases, safeguard animal health and welfare, and support food safety. However, used irresponsibly, this may have several negative impacts on human, animal and environmental health. In accordance with the one health concept, up to $90 \%$ of these antibiotics and/or their metabolites can be present as residues in food products from treated animals. Besides, it can be directly excreted which may lead to the development of antibiotic resistance in the environment [1]. The presence of these compounds represents several risks for consumers, in particular direct toxic effects, mutagenic and carcinogenic risks, allergic reactions, bacteriological risks, changes in the intestinal microbiota and the selection of resistant pathogenic bacteria [2, 3, 4].

Even if the direct toxicity of most used antibiotics is limited, absorption of even small daily doses of these drugs for long periods represents one of main public health concerns, which can cause harmful long-term effects [4, 5]. Allergic reactions represent one of the most important health risks since it is induced even by very low concentrations of antibiotics in food when withdrawal period is not respected [6]. $\beta$-lactams are the antibiotics that most frequently induce allergic accidents followed by sulfonamides and to a much lesser extent other antibiotics such as tetracyclines [3].

Public health services are concerned by the presence of antibiotic residues in milk and dairy products. Indeed, the allergic accidents in humans that occurafter the administration of $\beta$-lactams led to the establishment of severe regulations concerning the use of antibiotics in farm animals [3]. Moreover, regular ingestion of antibiotics induces digestive microbiota deregulations and the development of multiresistant bacterial strains. Furthermore, these strains constitute risks 
for both humans and animals since resistance plasmids could be transmitted to other bacterial pathogenic species [7].

On the other hand, the presence of antibiotic residues represents a big constraint for dairy industry that mostly relies on the action of milk microbial flora that is totally inhibited in the presence of antibiotic residues. In that case, technological accidents could occur leading to dairy product quality alteration and significant financial losses [8]. However, numerous regulatory measures were established in Tunisia to prevent the presence of antibiotic residues in quantities exceeding the maximum limits tolerated in food of animal origin intended for human consumption, among them the fixing maximum residue limits (MRLs) [9, 10]. The Tunisian government implemented a dairy sector development program aiming the prevention and the control of risks related to antibiotic residues presence in milk. Monitoring and control programs of residues in milk are performed every year by the Tunisian government [11].

In addition, the Tunisian ministries of agriculture and health implemented a national action plan to control antimicrobial resistance for 2019-2023 through a multi-sectorial approach, according to the one health concept integrating human, animal and environmental health [12]. The aim of the present study was to estimate the cattle bulk milk contamination rate with $\beta$-lactams in northeast Tunisian.

\section{Methods}

\subsection{Design and Sample}

Between July 2016 and June 2017, a total of 10.699 cow milk samples were collected from four governorates in Northern Tunisia, Jendouba ( $\mathrm{N}=6.720 ; 62.81 \%)$, Béja ( $\mathrm{N}=3.745 ; 35.00 \%)$, Kef $(\mathrm{N}=213 ; 1.99 \%)$ and Siliana $(\mathrm{N}=21$; $0.20 \%$ ) (see Figure 1). The overall milk production could be divided into two periods: high lactation period, during which green grass is available, from March to June and low lactation period, the demand of dairy industry is high in order to cover the milk yield decrease. The milk samples were collected from bulk milk, stored in identified sterile bottles and send to the laboratory at $+4^{\circ} \mathrm{C}$.

\section{$2.2 \beta$-lactams detection}

An enzymatic colorimetric test used for rapid detection of $\beta$-lactam antibiotics (penicillin and cephalosporin), Penzym ${ }^{\circledR}$ test (UCB-Bioproducts SA, Braine Lalleud, Belgium) was used since it is the official screening technique in Tunisia [7]. Indeed, penicillin and cephalosporin are two groups of antibiotic frequently used in Tunisia to prevent and treat livestock diseases [11].

Briefly, $50 \mu \mathrm{L}$ of each milk sample were mixed with $10 \mu \mathrm{l}$ of the DD-carboxypeptidase enzyme and incubated for 5 min at $47^{\circ} \mathrm{C}$. D-alanyl-D-alanine substrate was added to the mix, shacked and incubated at $47^{\circ} \mathrm{C}$ for 8 min. Milk samples were considered as negative if the concentration of $\beta$-lactams $<0.005 \mathrm{IU} / \mathrm{ml}$, doubtful if concentration of $\beta$-lactams $<0.008 \mathrm{IU} / \mathrm{ml}$ and positive if concentration of $\beta$-lactams $>0.017 \mathrm{IU} / \mathrm{ml}[13]$.

\section{Results}

Among the 10.699 analyzed milk samples, $14(0.13 \%)$ contained $\beta$-lactam residues. The percentage of milk containing $\beta$-lactams residues varied according to several factors (Figure 1).

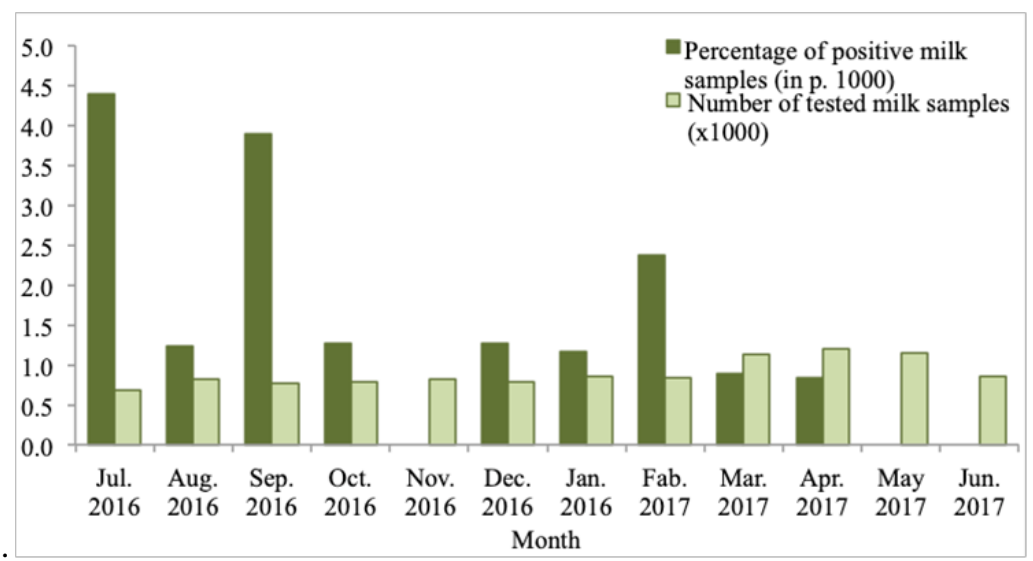

Figure 1. Monthly percentage of milk samples containing $\beta$-lactams' residues.

Considering different causes of milk refusal, a total of $3.874 .10^{3}$ liters of milk were refused (4.12\%). Among this quantity, $102.10^{3}$ liters $(2.64 \%)$ were seized due to presence of $\beta$-lactams' residues. The most important rates of antibiotic residues occurred during October and December which, corresponds with the low lactation period (Table 1). 
Table 1. Quantity of milk in litters collected and refused between July 2016 and June 2017

\begin{tabular}{|c|c|c|c|c|}
\hline Month & $\begin{array}{l}\text { Collected milk } \\
\qquad\left(1^{3} \mathrm{~L}\right)\end{array}$ & $\begin{array}{l}\text { Refused milk } \\
\quad\left(10^{3} \mathrm{~L}\right)\end{array}$ & $\begin{array}{c}\text { Refused milk for presence of } \\
\text { antibiotics }\left(10^{3} \mathrm{~L}\right)\end{array}$ & $\begin{array}{l}\text { Antibiotic refusal/total } \\
\text { refusal (\%) }\end{array}$ \\
\hline July 2016 & 7.258 & 197 & 16 & 8.1 \\
\hline August 2016 & 8.097 & 106 & 5 & 4.7 \\
\hline September 2016 & 7.148 & 153 & 12 & 7.8 \\
\hline October 2016 & 6.966 & 89 & 12 & 13.5 \\
\hline November 2016 & 6.492 & 46 & 0 & 0 \\
\hline December 2016 & 7.441 & 47 & 6 & 12.7 \\
\hline January 2017 & 7.587 & 309 & 24 & 7.7 \\
\hline February 2017 & 7.190 & 345 & 14 & 4.1 \\
\hline March 2017 & 9.914 & 501 & 6 & 1.2 \\
\hline April 2017 & 9.858 & 1.003 & 4 & 0.4 \\
\hline May 2017 & 9.741 & 529 & 0 & 0 \\
\hline June 2017 & 6.191 & 549 & 0 & 0 \\
\hline Total & 93.887 & 3.874 & 102 & 2.6 \\
\hline
\end{tabular}

The volume of refused milk according to different causes between March 2017 and June 2017 was high $\left(2.585 .10^{3} \mathrm{~L}\right)$, with a peak in April $\left(1.003 .10^{3} \mathrm{~L}\right)$. While the volume of refused milk during the same period for the presence of antibiotic residues was $10.10^{3} \mathrm{~L}$. Contrarily, between July and December 2016, the volume of milk refused for the presence of antibiotic residues was $51.10^{3} \mathrm{~L}$. Milk collected from Kef governorate had the highest level of antibiotic residues $(0.64 \%)$, followed by the governorate of Béja $(0.13 \%)$ and the governorate of Jendouba $(0.07 \%)$ (see Table 2$)$.

Table 2. Quantity of milk with positive results according to the quantity of milk refused for each region

\begin{tabular}{ccccc}
\hline Governorate & $\begin{array}{c}\text { Volume of milk } \\
\text { refused }\left(\mathbf{1 0}^{\mathbf{3}} \mathbf{L}\right)\end{array}$ & $\begin{array}{c}\text { Milk with antibiotic } \\
\text { residues }\left(\mathbf{1 0}^{\mathbf{3}} \mathbf{L}\right)\end{array}$ & $\begin{array}{c}\text { Milk with antibiotic resi- } \\
\text { dues/collected milk (\%) }\end{array}$ & $\begin{array}{c}\text { Milk with antibiotic resi- } \\
\text { dues/refused milk (\%) }\end{array}$ \\
\hline Jendouba & 1.822 & 43 & 0.07 & 2.4 \\
Béja & 1.861 & 44 & 0.13 & 2.39 \\
Kef & 173 & 15 & 0.64 & 8.46 \\
Siliana & 18 & 0 & 0 & 0 \\
Total & 3.874 & 102 & 0.11 & 2.64 \\
\hline
\end{tabular}

\section{Discussion}

The aim of the present work was to assess and quantify milk contamination by $\beta$-lactam residues in North West of Tunisia. In these regions, dairy cattle are suffering of high mastitis incidence which could explain the frequent use of antibiotics, particularly as self-medication. Tunisian North west governorates are characterized by a high number of small and medium-sized dairy farms kept by breeders with a relatively low technical skills, low awareness to the issue of drug residues in animal products. Samples were collected throughout the year, including both the low and the high lactation periods.

A total of 10.699 milk samples were tested, among them, 14 were positive $(0.13 \%)$. These samples contained $\beta$-lactam concentrations higher than $0.017 \mathrm{IU} / \mathrm{ml}$ of milk. Similar study was carried out in Tunisia in the governorate of Béja, and indicated that out of 50 analyzed milk samples by the Delvotest ${ }^{\circledR}$ test, 20 samples were positive [14]. The discrepancy between these results could be explained by the strengthening of residue control which is not systematically done at that time. In addition, Ouertani [14] used Delvotest ${ }^{\circledR}$, allowing the detection of a larger number of antibiotics than the Penzym ${ }^{\circledR}$ test.

In central-eastern Tunisia (Monastir governorate) between May and July 2011, Fekih [15] showed that out of 1.213 analyzed samples, 139 contained residues of antibiotics (11\%). In 2013, Mathlouthi [16] investigated the presence of 
antibiotic residues in milk using the Delvotest ${ }^{\circledR}$ kit in 25 bulk milk samples, four of them were doubtful and no positive samples were detected. The low prevalence of contaminated milk could be explained by the small size of the samples. In addition, Delvotest ${ }^{\circledR}$ is a broad-spectrum microbiological test, detecting residues of anti-infection drugs in milk at levels close to MRLs.

Lahmar and Ben Youssef [17], tested 11.551 milk samples using Penzym ${ }^{\circledR}$ in the governorate of Béja (North west Tunisia) between March and July 2016, 42 of them were positive $(0.36 \%)$.This positivity rate was very close to our results $(0.13 \%)$ showing a good quality of cattle milk in north Tunisia. Aggad et al. [18] reported a high rate (29\%) of antibiotic residues in milk samples collected from the wilaya of M'sila, northeast Algeria. Debeche et al. [19] reported between January and July 2017 that $3.25 \%$ of the 10.153 bulk samples analyzed of raw milk containing $\beta$-lactam residues in this same region.

In central Algeria, a recent study showed that $12.67 \%$ of milk samples were contaminated with inhibitory substances. Residues of $\beta$-lactam were present in 26.32\% of analyzed samples [20]. In Benin, Mensah et al. [21] reported that more than $50 \%$ of cow's milk samples contained antibiotic residues. These results were similar to those reported in Kosovo by Sulejmani et al. [22]. In Romania, Pogurschi et al. [23] aimed to assess the residues of antibiotics in raw milk from dairy and processed milk producers. Of the 210 tested milk samples, antibiotic residues were detected in 42 samples, including 12 containing $\beta$-lactams.

In the present study, the positivity rate $(0.13 \%)$ seems to be low, but in reality, it represents a high milk volume $\left(102.10^{3}\right.$ litres $)$ and subsequently its seizures induce significant financial losses. This relatively low contamination rate reflects an improvement in the quality of the milk in terms of antibiotic residues, mainly due to the compulsory systematic antibiotic residue monitoring system carried out in Tunisia. Contaminated milk samples are bulk milk collected from several farms. Some farmers dilute milk from treated cows to sell it below the detection threshold of the Penzym ${ }^{\circledR}$ test.

The present results confirm the role of three main stakeholders in the milk industry, the farmer, veterinarians and the dairy industry in reducing the presence of antibiotic residues in milk. The use of antibiotics in production animals should be managed in accordance in respect to the One Health approach. Even if the number of samples of contaminated milk was small in the present study, the volume of refused milk was significant. Residues of $\beta$-lactam antibiotics in milk represent a real threat to consumers. In Tunisia, a national strategy for systematic investigation and monitoring of drug residues in all food products of animal origin is a priority that could be performed in an integrated approach.

\section{Conclusion}

Briefly stated, this study identifies a high self-assessment (over-evaluation) in connection with HH and positive attitudes and perceptions of the importance of $\mathrm{HH}$ among majority of HW. The phenomenon of self-assessment and attitudes of HW in compliance with $\mathrm{HH}$ should be included in future educational strategies. Self-assessment is a skill that is for HW one of another career development and as such it can be considered for attribution of an expertise and professionalism. It is likely that the practice of self-assessment through reflections and motivational interviews could enable to get an overview of compliance with HR with the aim to identify strengths and areas for further development of strategies in relation to the prevention of NI and safe healthcare. Self-assessment is an essential component of competence in hand hygiene.

There are various techniques mentioned in the literature, including critical incidents and reflective methods that are used to improve the practice of self-reflection and self-assessment. It is recommended as a part of educational strategy techniques to improve self-esteem, interpersonal relationships critical analysis of the clinical cognitive learning and logical thinking. TTM should be used as the interventionist paradigm of motivational interviewing and could be borrowed and adapted from health promotion and applied to hand hygiene as their function, to increase understanding and enhance motivation in order to achieve sustainable behavioural change. They are attributes which have resonance for a challenging problem like hand hygiene compliance. Also, efficient education and active self-management are considered as major interventions that should lead to changes in attitudes and personal responsibility in the implementation of $\mathrm{HH}$ in the clinical practice.

\section{Conflict of interest}

The authors declare that they have no conflict of interest regarding the publication of this article.

\section{References}

[1] Lefeuvre, C. (2003). The management of sanitary risks induced by the veterinary medicine: Place of the traceability. National School of Public Health, 36, 1-10.

[2] Bada Alambedji, R., Akapko, A. J., Teko-Agbo, A., Chataigner, B., Stevens, A., Garin, B. (2008). Residue control: example of 
antibiotics in food in Senegal, OIE Conference on Veterinary Medicinal Products in Africa, Dakar, 5, 25-27.

[3] Chataigner, B. and Stevens, A. (2002). Investigation into the presence of antibiotic residues in meat marketed in Dakar, Pasteur Institute of Dakar, project PACEPA, 45, 234-141.

[4] El Bahri, L., Ben Hassine, T., and Belghith, J. (2007). Antibiotic therapy in laying hens and the risk of antibiotic residues for the consumer. El Baytary, 45, 5-6.

[5] Rico, A. G. and Burgat-Sacaze, V. (1984). Veterinary medicines and food safety. Toxicological approach. Rev. Sci. Tech. Off. Int. Epiz., 3, 855-867.

[6] Abbal, M. (1998). Immunological mechanisms of reaction to antibiotics. Rev. Fr. Allerg. Immunol. Clin., 38, 367-373.

[7] Form, G. (2003). Inhibitor residues in milk: evolution of detection methods, risk factors in the Rhône-Alpes region. DVM dissertation, University Claude Bernard, Lyon.87, 102-109.

[8] Fabre, J. M., Moretain, J. P., and Berthelot, X. (2002). Evolution of the interprofessional method for the detection of antibiotic residues in milk. GVT Newsletter, 15, 26-28.

[9] Ben Youssef, S. and Boujelbene, S. (2012). Al Baytar, Dictionary of Veterinary Medicines of Tunisia, National School of Veterinary Medicine, Sidi Thabet, Tunisia.

[10] Puyt, J. D. and Faublee, V. (2007). Anti-infective drugs in veterinary medicine, basics of antibiotic therapy. Edition 2007, ONIRIS, Nantes.

[11] General Directorate of Veterinary Services (D.G.S.V.). (2009). Memorandum n 200/1093 of 7 May2009 on specific monitoring plan for the detection of residues in cow's milk.

[12] WHO. (2018). World Health Organization. Global antimicrobial resistance surveillance system. http://www.who.int/glass/ resources/publications. Accessed on 30 December 2017.

[13] Brouillet, P. (2002). Rapid tests for the detection of antibiotics in milk. Bull. Group. Tech. Vét., 15, 183-189.

[14] Ouertani, H. (2003). Antibiotic residues in milk: Survey in a collection center in the region of Beja. DVM dissertation. National School of Veterinary Medicine, Sidi Thabet, 45-51.

[15] Fekih, M. (2013). Residues of $\beta$-lactamines in milk collected by the Essaada cooperative, Teboulba, DVM dissertation. National School of Veterinary Medicine, Sidi Thabet, 38.

[16] Mathlouthi, O. (2013). Milk peddling channels and antibiotic residues. DVM dissertation. National School of Veterinary Medicine, Sidi Thabet, 46.

[17] Lahmar, R. and Ben Youssef, S. (2018). Residues of $\beta$-lactams in milk collected in Beja, Tunisia. $2^{\text {nd }}$ Congress of the National School of Veterinary Medicine of Sidi Thabet. 25-26.

[18] Aggad, H., Mahouz, F., Ahmed, A. Y., and Kihal, M. (2009). Evaluation of the hygienic quality of milk in western Algeria. J. Vet.Med., 160, 595-601.

[19] Debeche, E. H., Ghozlane, F., and Madani, T. (2018). Importance of certain residues of antibiotics in cow's milk in Algeria. Case of the wilaya of M'sila. Livestock Res. Rur Dev., 30, 125-132.

[20] Baazize-Ammi, D., Dechicha, A. S., Tassist, A., Gharbi, I., Kebbal, S., Morsli, W., Beldjoudi, S., Saadaoui, M. R., Guetarni, D. (2019). Research and quantification of antibiotic residues in the muscle of broilers and in milk in the central region of Algeria. Rev. Sci. Tech. Off. Int. Epiz., 38, 102-108.

[21] Mensah, S. E. P., Aboh, A. B., Salifou, S., Mensah, G. A., Sanders, P., Abiola, F. A., and Koudandé, O. D. (2014). Risks due to antibiotic residues detected in cow's milk produced in central Benin. J. App. Biosc., 80, 7102-7112.

[22] Sulejmani, Z., Shehi, A., Hajrulai, Z., and Mata, E. (2012). Abuse of pharmaceutical drugs antibiotics in dairy cattle in Kossovo and detection of their residues in milk. J. Ecosyst. Ecogr., 2, 96-110.

[23] Pogurschi, E., Ciric, A., Zugrav, C., and Patrascu, D. (2015). Identification of Antibiotics Residues in Raw Milk samples Coming from The Metropolitan Area of Bucharest. Elsevier- Agriculture and Agri Sci Pro., 6, 242-245. 